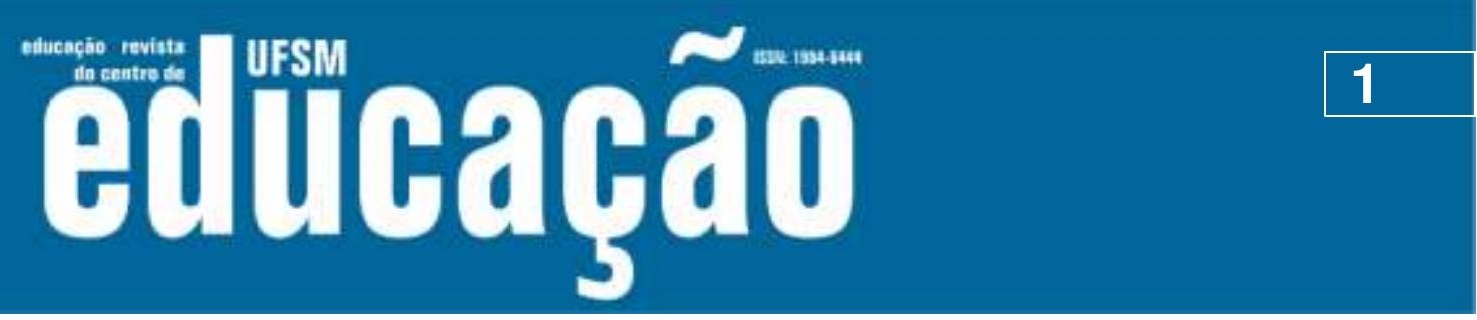

ISSN: 1984-6444 | http://dx.doi.org/10.5902/1984644435899

\title{
A luta pela terra e experiência de infância em um acampamento de reforma agrária
}

\author{
The struggle for land and the childhood experience in an agrarian reform \\ camp
}

\author{
Fábio Accardo Freitas \\ Universidade Federal de Minas Gerais \\ Ana Lúcia Goulart de Faria \\ Universidade Estadual de Campinas
}

\section{RESUMO}

O presente texto tem como objetivo compreender a maneira pela qual as crianças Sem Terrinha do acampamento Elizabeth Teixeira, em Limeira-SP, além de sujeitos testemunhas passam a ser protagonistas da luta pela terra. A pesquisa teve como espaço e tempo de observação as atividades educativas da Ciranda Infantil, entre 2010 e 2014. A terra foi ocupada em abril de 2007, foram despejados/as violentamente em novembro do mesmo ano e voltaram a reocupar a terra em dezembro. As crianças vivenciaram todo esse processo. Elas trazem esses elementos e memórias que se transformam em brincadeiras na Ciranda Infantil. Com o processo de reorganização interna da área, a Ciranda Infantil tornou-se um dos poucos espaços de vivência do coletivo infantil do acampamento. Lugar em que a maioria das crianças podiam se encontrar, brincar, discutir, aprender, produzir as culturas infantis participando da construção da realidade social. As questões deste artigo são provenientes do trabalho educativo e investigativo realizado por um dos autores com as crianças Sem Terrinha em um acampamento de reforma agrária. Os processos vivenciados pelas crianças são foco deste texto que, a partir das observações e relatos das atividades com as crianças proveniente do exercício etnográfico do/a pesquisador/a, coloca em evidência os seus pontos de vista, possibilitando falarem de si e de suas experiências de infância no acampamento, assim como das possibilidades de transformação da realidade em que vivem, da luta por direitos e de sua constituição como sujeitos e protagonistas da história e da luta pela terra.

Palavras-chave: Infâncias; Culturas infantis; Movimentos sociais.

\section{ABSTRACT}

This paper aims to comprehend the way through which the Landless Kids from the camp Elizabeth Teixeira in Limeira-SP, besides witness subjects, are seen by the researcher as protagonists of the struggle for land. The research had as space and time of observation the educative activities at Ciranda Infantil, between 2010 and 2014. The land was occupied in April 2017, they were violently evicted on November same year and returned to reoccupy the land on December. The children have experienced 


\section{Lusm oittrabat}

ISSN: 1984-6444 | http://dx.doi.org/10.5902/1984644435899

Compõem o acampamento cerca de 60 crianças de 0 a 12 anos, filhos e filhas das 100 famílias que lá vivem. A terra foi ocupada em abril de 2007, foram despejados/as violentamente em novembro do mesmo ano e voltaram a reocupar a terra em dezembro. Após onze anos vivendo embaixo da lona preta, a área foi afirmada como de interesse social e o acampamento está prestes a se regularizar. As crianças vivenciaram todo esse processo. Elas contam as lembranças da ocupação, dos fatos marcantes do despejo e da reocupação. Elementos e memórias que se transformam em brincadeiras na Ciranda Infantil.

As questões aqui colocadas são provenientes do trabalho educativo e investigativo realizado pelo autor com as crianças Sem Terrinha em um acampamento de reforma agrária ${ }^{1}$. Reflexão e prática em que as crianças foram modificando o olhar adultocêntrico do pesquisador, apresentando as suas realidades e se colocando como ativos/as pequenos/as sujeitos no mundo e da construção e resistência daquele acampamento. Ao reconhecer as crianças como sujeitos, pode-se observar a produção das culturas infantis, suas produções de significados e interpretações do mundo, através das brincadeiras e atividades realizadas na Ciranda Infantil.

Os processos vivenciados pelas crianças são foco deste texto, que tem como fundamento e pano de fundo as observações e relatos das atividades com as crianças proveniente do exercício etnográfico do pesquisador, o qual coloca em evidência os pontos de vistas das crianças, que possibilitam falarem de si mesmas e de suas experiências de infância no acampamento, assim como das possibilidades de transformação da realidade em que vivem, da luta por direitos e de sua constituição como sujeitos e protagonistas da história e da luta pela terra.

\section{Ciranda Infantil como espaço de produção de culturas infantis}

A luta pela terra é uma luta em família. Mulheres, homens, adultos, idosos e crianças, compartilham a experiência da luta. No entanto, as crianças sempre foram reconhecidas como testemunhas da luta de suas famílias, acompanhando e sofrendo

\footnotetext{
1 Pesquisa de mestrado do autor deste artigo, intitulada "Educação Infantil Popular: possibilidades a partir da Ciranda Infantil do MST", realizada junto ao grupo de pesquisa GEPEDISC - Culturas Infantis, da Faculdade de Educação da Unicamp - SP, sob orientação da Profa. Dra. Ana Lúcia Goulart de Faria. Disponível em: <http://repositorio.unicamp.br/handle/REPOSIP/254003>
} 


\title{
Lusm Eutibarat
}

ISSN: 1984-6444 | http://dx.doi.org/10.5902/1984644435899

a cada ocupação, acampamento, assentamento, mas sem destaque na cena ou enredo da ação (CALDART, 2012). O trabalho e a pesquisa modificou essa visão adultocêntrica das crianças Sem Terrinhas, as quais, também no interior do MST, ocuparam o lugar de sujeitos da luta pela terra, onde

\begin{abstract}
as crianças começam a entrar em cena como personagens que criam seus próprios espetáculos, exigindo seus direitos também como integrantes desse Movimento e dessa organização social que vem produzindo sua identidade específica. É nessa condição também que começam a se organizar para reivindicar seus direitos ou fazer negociações em sua própria comunidade de assentamento ou acampamento, causando surpresa e provocando a reflexão de seus próprios pais (...) (CALDART, 2012, p. 306 - 308)
\end{abstract}

No acampamento Elizabeth Teixeira não foi diferente. As crianças vivenciaram, como sujeitos, os processos de ocupação, despejo, reocupação, organização interna e construção coletiva do acampamento. Contudo, no início, o espaço do acampamento era o lugar compartilhado de vivência das crianças entre elas. As famílias viviam muito próximas e existiam espaços coletivos, como barracão central e a "ciranda redonda" com parquinho, onde as pessoas se encontravam frequentemente, inclusive as crianças que podiam estar todo o tempo juntas.

Com o primeiro processo de regulamentação da área, em 2008, decidiu-se pelos lotes individuais, no qual cada família tem a sua casa e seu espaço de produção. Fato que impactou a relação entre as crianças no acampamento, tornando-se evidente o afastamento do convívio coletivo e cotidiano entre elas, surgindo outras formas de se relacionarem, em outros espaços, com novas tramas de relações.

Há um reflexo disso nos poucos espaços coletivos de convivência cotidiana das crianças. A maioria das vezes, as crianças compartilham os momentos coletivos dos adultos e aproveitam para se encontrar e brincar. As reuniões, assembleias, cultos das igrejas católica e evangélica, aulas da Educação de Jovens e Adultos (EJA), festas, momentos de receber doações de alimentos (cestas básicas), de roupas ou o ônibus da escola viraram espaços de "encontro" das crianças do acampamento.

A Ciranda Infantil, a partir desse contexto, foi tornando-se um dos poucos espaços de vivência do coletivo infantil do acampamento. Lugar em que a maioria das crianças podem se encontrar, brincar, discutir, aprender, imaginar, criar e, portanto, 


\title{
$=1 \mathrm{sism}$

ISSN: 1984-6444 | http://dx.doi.org/10.5902/1984644435899

produzir as culturas infantis (FERNANDES, 2004) participando da construção da realidade social.

Espaço e tempo pensado intencionalmente para o encontro das crianças do acampamento, um dos elementos destacados pelo o projeto educativo do MST.

\begin{abstract}
Através das vivências no coletivo infantil as crianças têm possibilidades de se apropriar dos elementos do processo histórico para a compreensão da realidade. Dessa forma, as crianças vão construindo o coletivo infantil juntamente com os educadores e educadoras no processo pedagógico e a Ciranda Infantil tem possibilidade de ser a base deste coletivo infantil. (ROSSETTO, 2009, p. 18)
\end{abstract}

As atividades da Ciranda Infantil, por acontecerem aos sábados pela manhã, possibilitam o encontro da maioria das crianças do acampamento, ao mesmo tempo que também traz algumas limitações, pois é um tempo restrito de encontro do coletivo de crianças.

No entanto, existe uma vinculação muito forte entre a vida cotidiana das crianças no acampamento e as atividades da Ciranda Infantil, que são vistas como um alargamento da vida naquela comunidade. Esta simbiose entre educação e vida faz com que esse intervalo entre uma atividade e outra da Ciranda Infantil seja completado pelas vivências cotidianas do acampamento, compartilhando as práticas culturais entre adultos e crianças, constituindo também a sua experiência de infância Sem Terrinha.

A existência da Ciranda Infantil no acampamento possibilita que as crianças possam reelaborar as suas experiências de ser crianças ali, dentro de uma história de luta compartilhada e das condições concretas vividas. Espaço onde as suas experiências individuais vão se tornando coletivas a medida em que as crianças vão compreendendo seu lugar no mundo, a sua condição de classe, de pertença a um movimento social organizado que luta por transformações sociais. Assim, o MST define Ciranda Infantil como

Um espaço educativo organizado, com objetivo de trabalhar as várias dimensões de ser criança Sem Terrinha, como sujeito de direitos, com valores, imaginação, fantasia, vinculando as vivências do cotidiano, as relações de gênero, a cooperação, a criticidade, e a autonomia (...). É muito mais que espaços físicos, são espaços de trocas, aprendizados e vivências de novas relações. (MST, 2004, p.37) 


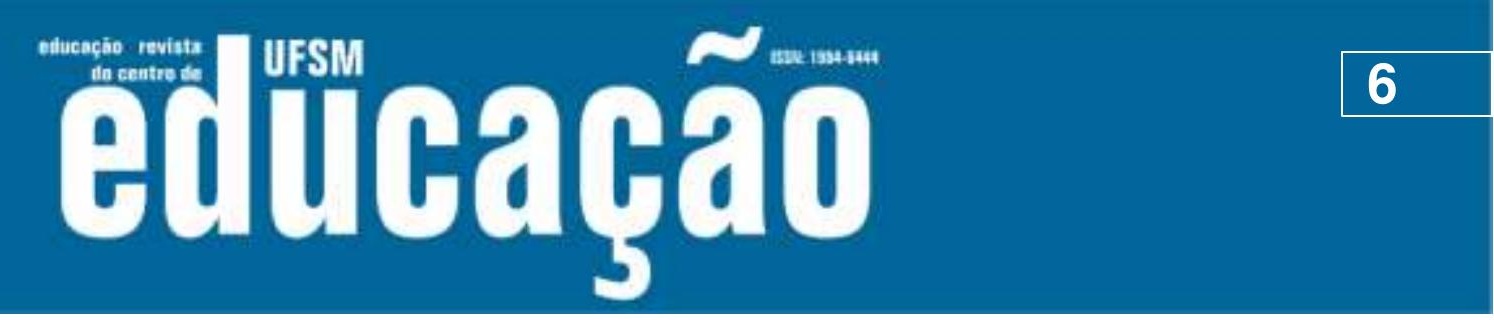

ISSN: 1984-6444 | http://dx.doi.org/10.5902/1984644435899

Dentro desse processo de pesquisa, compreendeu-se que as relações das crianças entre elas e entre elas e os adultos, na Ciranda Infantil, podem ser vistas como produção de culturas infantis próprias daquele contexto. Florestan Fernandes (2004) reconhece que as crianças produzem cultura infantil, na relação entre as crianças, por meio das brincadeiras, ou seja,

(...) existe uma cultura infantil - uma cultura constituída de elementos culturais quase exclusivos dos imaturos e caracterizados por sua natureza lúdica atual (...), cujo suporte social consiste nos grupos infantis, em que as crianças adquirem, em interação, os diversos elementos do folclore infantil. (FERNANDES, 2004, p. 215)

Para pensar as crianças e as culturas infantis, a pesquisa trouxe a necessidade de se trabalhar com as diferentes concepções de infância - rural, urbana, quilombola, ribeirinha, indígena, do campo, negra, das meninas e dos meninos, rica, pobre, Sem Terrinha, etc - no sentido de ampliar o conceito de cultura infantil, tratando de falar em culturas infantis, no plural.

Vale também articularmos à essa discussão o conceito de reprodução interpretativa $^{2}$ (CORSARO, 2011) que reconhece a atividade coletiva e conjunta das crianças entre seus pares e com os adultos e como elas negociam, produzem, compartilham e criam cultura em suas relações cotidianas. Ao se relacionarem com a cultura adulta, as crianças as reinterpretam ativamente e produzem novos significados, isto é, produzem as culturas infantis (em inglês o autor utiliza peer culture, cultura de pares ${ }^{3)}$.

\footnotetext{
2 William Corsaro constrói o conceito de reprodução interpretativa destacando como as crianças participam ativa e coletivamente da sociedade. O foco muda da internalização individual dos conhecimentos do mundo adulto pelas crianças e centra-se na sua participação na produção e reprodução cultural. O termo interpretativo evidencia os "aspectos inovadores e criativos da participação infantil na sociedade." (CORSARO, 2011, p. 31, grifos no original), enquanto o termo reprodução traz a ideia de que as crianças são integrantes de uma estrutura social, e que a infância vivida por elas é afetada por essa sociedade e cultura da qual fazem parte. Assim, a reprodução interpretativa trabalha a ideia de que as crianças também "criam e participam de suas próprias e exclusivas culturas de pares quando selecionam ou se apropriam criativamente de informações do mundo adulto para lidar com suas próprias e exclusivas preocupações." (Idem, p. 31).
}

${ }^{3}$ Cultura de pares refere-se a cultura produzida nas relações e atividades coletivas entre as crianças fora do âmbito familiar. William Corsaro (2011, p. 128) utiliza o conceito de peer culture equivalente ao conceito de "cultura infantil" cunhado por Florestan Fernandes, trabalhado neste artigo. 


\section{Autuaŗão}

ISSN: 1984-6444 | http://dx.doi.org/10.5902/1984644435899

Diante desses dois conceitos, entende-se a Ciranda Infantil como espaço de produção de culturas infantis e de convivência do coletivo infantil das crianças que vivem no acampamento Elizabeth Teixeira. Nessa perspectiva, podemos entender as crianças como sujeitos capazes de criar novas relações sociais coletivas e de criarem espaços nos quais vão construindo hoje as possibilidades e utopias para uma outra sociedade.

A partir dessa compreensão, das crianças como sujeitos no mundo, que compartilham as culturas infantis, a vivência e observação das crianças no acampamento Elizabeth Teixeira trouxe elementos para compreender a maneira como elas vão se constituindo como sujeitos e protagonistas da luta pela terra.

\section{Culturas infantis: a identidade com a terra}

No início das atividades da Ciranda Infantil do ano de 2010 se realizou uma reunião com mães e pais onde se definiu a temática a ser trabalhada com as crianças: a identidade com a terra. O tema surgiu a partir da constatação que algumas crianças do acampamento tinham uma vivência urbana, e a trajetória de vida dessas crianças se diferenciava daquelas com a trajetória do mundo rural.

A partir da definição do tema, diversas atividades foram planejadas, que marcaram o início de uma temática que se estendeu por outros anos, em diversos momentos da Ciranda Infantil. Temática que entrelaça a história da comunidade e das crianças desde o processo de ocupação até hoje.

Muitas famílias que chegam nas ocupações de terra nem sempre têm uma trajetória diretamente vinculada à vida no campo. Tal fato aponta uma dificuldade de (re)criar o vínculo dessas famílias com a terra e, principalmente, da permanência das crianças e jovens no campo.

As atividades propostas na Ciranda Infantil foram pensadas para que as crianças pudessem conhecer a sua história, seu passado, as lutas de suas famílias e que se reconheçam como parte e sujeitos dessa história de lutas. Intencionalidade que contribui também para o construção do pertencimento Sem Terrinha e materializa a prática de uma Educação Infantil Popular emancipatória. 


\title{
L oitibabat
}

ISSN: 1984-6444 | http://dx.doi.org/10.5902/1984644435899

A temática da identidade com a terra trouxe novas perspectivas de abordar questões concernentes a essa realidade da infância, na tentativa de construir coletivamente com as crianças, sua identidade Sem Terrinha, sua relação com a terra, sua coletividade infantil e a sua participação como pequenos sujeitos na história do acampamento.

Assim, as atividades foram iniciadas com a ideia de construção de uma horta das crianças na área do lote coletivo, perto do barracão social. À essa atividade somou-se a atividade da composteira, com relação aos resíduos orgânicos do café da manhã da Ciranda Infantil que podiam virar adubo para a horta. Essas primeiras atividades se desdobraram em outras, como veremos: oficina de mudas de manga e de como fazer enxertos no viveiro de mudas do lote de um dos agricultores acampados.

\section{Horta coletiva das crianças e composteira}

Tendo como ponto de partida a temática identidade com a terra, as educadoras e educadores infantis decidiram propor a realização de uma horta coletiva das crianças, vista como uma atividade prática em que as crianças pudessem trazer os saberes que aprendem com mães e pais, em que pudessem plantar, regar, cuidar, colher, criando uma relação e identidade das crianças com o trabalho na terra, a partir da sua própria produção.

Na primeira atividade proposta, um dos educadores inventou que ele tinha uma minhoca de estimação chamada Juca, de quem cuidava todos os dias, dando comida, afofando a terra, para que a sua minhoca pudesse viver feliz. A história instigou a curiosidade das crianças para conhecer a minhoca de estimação.

\begin{abstract}
pudemos levantar alguns questionamentos sobre o plantar, a importância de arar a terra e o trabalho da minhoca. O Fernando ${ }^{4}$, Vinícius e outros meninos depois da Ciranda desceram até a mina d'água para pescar e disseram que não iam levar minhoca, pois gostaram da história e viram a importância dela para a terra. (Relato de atividade da Ciranda Infantil, 27/03/2010)
\end{abstract}

Nas semanas seguintes as crianças ficavam perguntando quando íamos trazer o Juca para elas conhecerem. A oportunidade veio quando começou a conversa com

\footnotetext{
${ }^{4} \mathrm{O}$ nome das crianças e das educadoras e educadores são nomes fictícios e foram escolhidos por cada um no processo das atividades e da finalização da pesquisa.
} 


\section{Usm

ISSN: 1984-6444 | http://dx.doi.org/10.5902/1984644435899

as crianças sobre construirmos uma horta coletiva com elas. As crianças se animaram muito.

Propusemos a eles um desenho coletivo para iniciarmos a hortinha com a casa do Juca [o pé de manjericão]. Depois do desenho, fomos colocar o manjericão com o Juca no barracão junto com a plaquinha que fizemos da casa dele. Escolhemos um cantinho e combinamos de regarmos o Juca e o manjericão todo dia. (Relato de atividade da Ciranda Infantil, 17/04/2010)

A ideia da horta das crianças estava começando a se concretizar. As educadoras e educadores pensaram em compor a atividade da horta com a construção de uma composteira para reutilizar os resíduos orgânicos do café da manhã que eram descartados, produzindo adubo para usar na horta das crianças.

(...) Perguntamos: porque seus pais fazem horta? O que eles plantam? (...) Conversamos um pouco sobre o adubo; perguntamos o que é preciso para se fazer uma horta, responderam: esterco de vaca! Daí nós perguntamos o que os pais deles faziam com os restos de frutas, as cascas etc. Eles disseram que jogavam na terra, espalhados... eu e o Anakin fizemos o maior drama: falamos que nós não fazíamos daquele jeito, e que nós tínhamos um grande segredo!!! Eles ficaram super curiosos! Contamos que o segredo era colocar tudo junto, concentrado em um buraco e com palha para não feder.

Fizemos o buraco. O Anakin, Ronaldo, eu e Tereza revezamos e ficou lindo o buraco. Picamos os compostos que podiam ir na composteira pequenininhos. E na hora que íamos colocar o Juca (que estava no vaso de manjericão) chegou a Joana com um monte de crianças (Leandro, Helena, Roseli, Vanessa, Pedro e mais alguns que esqueci). Foi legal, contamos para eles porque estávamos fazendo aquilo, e eles ficaram bem interessados...prestaram bastante atenção! Cobrimos a composteira com palha, colocamos o Juca e o Roberval (outra minhoca amiga do Juca) na composteira e fomos fazer os cartazes. Os pequenos ficaram fazendo o cartaz que dizia o que podia ir para a composteira e a Tereza, Vanessa e Helena escreveram: Composteira da Ciranda (adubo). (Relato de atividade da Ciranda Infantil, 24/04/2010)

A composteira foi utilizada durante algum tempo, mesmo depois que as atividades da horta das crianças pararam. Contudo, as crianças não esqueceram da prática de reutilizar os resíduos orgânicos para adubar as plantas.

Após essa atividade as educadoras e educadores infantis entenderam que as crianças estavam bastante envolvidas e que seria interessante dar início à horta das crianças. Prepararam uma atividade só para isso: decidiriam coletivamente o lugar onde seria feita a horta, levariam algumas ferramentas para usarem com as crianças para limpar, capinar e preparar a terra e água para regar as sementes e mudas que 


\title{
Lusm

ISSN: 1984-6444 | http://dx.doi.org/10.5902/1984644435899

fossem plantadas. Contudo, tiveram uma surpresa quando chegaram para a atividade no outro sábado de manhã.

\begin{abstract}
O Fernando e mais dois (...) plantaram na horta. Estavam super contentes, contaram tudo o que plantaram: alface, cebolinha, cebola e almeirão. Eles limparam, fizeram os canteiros e estavam revezando para regar, mas não estava dando certo porque precisava ter um galão perto da horta para o caminhão-pipa abastecer; e o revezamento não estava dando certo, a Roberta não estava regando, eles relataram, mas ela não estava lá para se defender. (...) Eles estão esperando mais sementes, de cenoura que a tia Luiza vai arrumar, e as mudinhas do Fernando, que de acordo com eles, estão pequenas ainda. A Noele queria plantar flor, mas os meninos não deixaram porque senão estraga as outras mudas, espalha a semente e vira mato. Eles mesmos resolverem isso. (Relato de atividade da Ciranda Infantil, 02/05/2010)
\end{abstract}

A ideia de ensinar aquelas crianças a fazerem uma horta coletiva se mostrou um equívoco. Ainda que algumas crianças não tenham uma história familiar vinculada à terra, aquelas famílias já viviam no acampamento por quase três anos. As famílias, desde o início, começaram a produzir alimentos na área e as crianças aprenderam juntamente com suas mães e pais a plantarem.

Percebeu-se que a horta para elas era ao mesmo tempo uma brincadeira e uma responsabilidade. Gostavam de brincar de mexer com a terra. Mostraram isso com o Juca, depois com a composteira e também por terem construído sozinhas a própria horta. E tomaram-na como uma responsabilidade delas, de fazer acontecer, de dividir as tarefas para cuidar, para regar. Discutiam o que podia ou não plantar, o que era melhor e até ficavam bravas umas com as outras se estragavam o plantio.

Mostraram também para as educadoras e educadores que entendiam os problemas estruturais do acampamento, como a falta de água, que dificultava a organização delas para trabalhar na horta, uma vez que não tinham um galão onde podiam armazenar água para regar a plantação adequadamente.

Além de criarem canteiros para plantar algumas verduras e legumes, as crianças criaram um sistema de irrigação com garrafas de plástico. Fizeram uma estrutura com algumas ripas de madeira onde amarraram barbantes para sustentar as garrafas com a boca para baixo. Em cada tampinha das garrafas havia um furo para gotejar a água colocada ali dentro. As crianças reinventaram, ao seu modo, a técnica de irrigação por gotejamento, muito usada na produção agrícola. 


\section{Tusw $\sim$

ISSN: 1984-6444 | http://dx.doi.org/10.5902/1984644435899

A horta não durou muito tempo. As crianças não conseguiram se organizar entre elas para os cuidados necessários e a periodicidade das atividades não contribuiu para que a horta se tornasse um tema para diversas outras atividades da Ciranda Infantil. As mudinhas morreram, mas a experiência ficou marcada nas crianças, que lembram sempre da música que criaram naquele dia que as crianças mostraram a horta que haviam feito sozinhas:

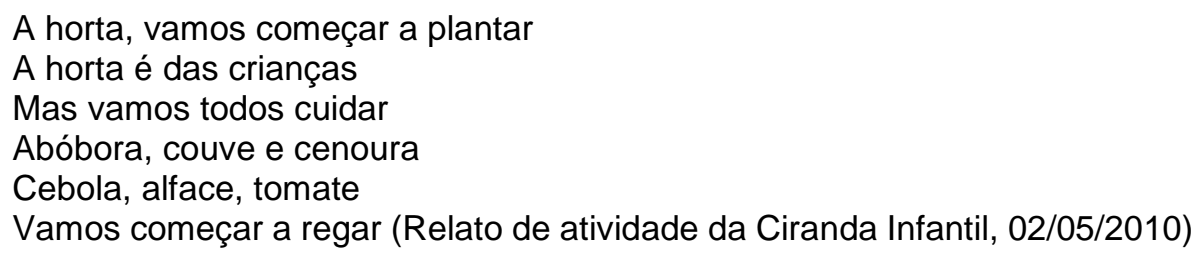

\section{Viveiro pedagógico de mudas, mangas e enxertos}

Nos anos seguintes outras atividades relacionadas ao tema da identidade com a terra aconteceram, principalmente a partir da relação com um dos acampados. Seu Chamaru $^{5}$, desde sempre, dizia que seu sonho era conseguir um espaço para que pudesse realizar atividades educativas relacionadas à produção agrícola.

Alguns membros do coletivo Universidade Popular realizaram um projeto de construção de um viveiro pedagógico de mudas no lote do Seu Chamaru, como um espaço para educar as crianças sobre a importância da terra e da organização da produção de mudas para garantir o plantio e alimentos para a comunidade, respeitando a natureza e seu ciclo.

De uma conversa com esse acampado surgiu a ideia da atividade com as crianças de plantar mudas de árvores nativas na beira da mina d'água, uma das nascentes do rio Tatu, pensando na preservação ambiental e o cuidado com a nascente e o rio que ficam na área do acampamento.

As educadoras e educadores da Ciranda Infantil propuseram também algumas atividades que pudessem estar relacionadas com o viveiro de mudas. Isso garantia uma vivência das crianças em outros lugares do acampamento, assim como trabalhar

\footnotetext{
${ }^{5} \mathrm{O}$ agricultor acampado que construiu o viveiro de mudas pediu para ser chamado na pesquisa de Seu Chamaru, em lembrança à atividade realizada com as crianças no viveiro. Chamaru é o nome do monstro que faz enxerto, criado pelas crianças na atividade da Ciranda Infantil, como veremos no decorrer do artigo. Para distinguir utilizei o prenome "Seu" para o nome do assentado.
} 


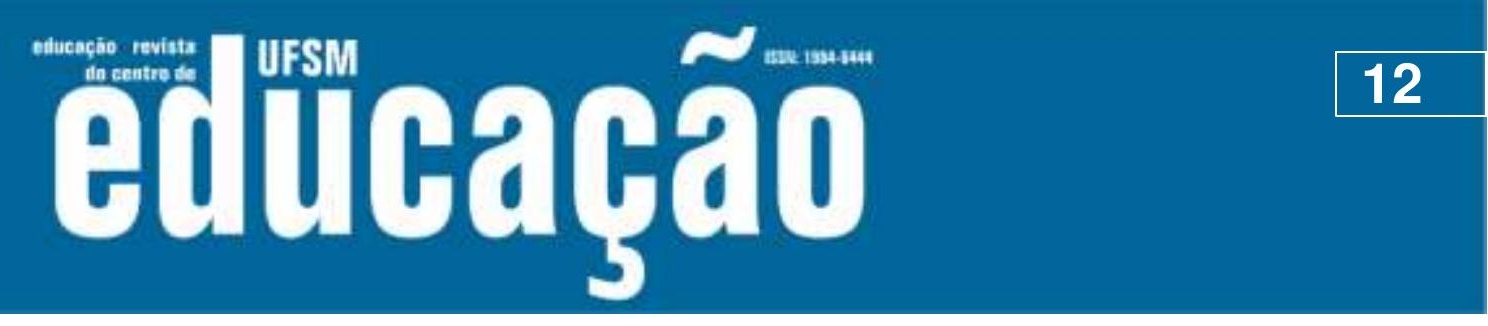

ISSN: 1984-6444 | http://dx.doi.org/10.5902/1984644435899

o respeito e importância pelo saber de um acampado mais velho da comunidade e a

identidade das crianças com as atividades produtivas da comunidade.

(...) eles também foram escutar a história das mangas de Chade, na África. Antes de iniciar a história, Luiza pegou uns panos na kombi e esticou no chão, preparando o terreno pra história, algo mais aconchegante, e ficou responsável pelos efeitos sonoros enquanto eu contava a história (...). Ouvimos a história e comemos mangas ao mesmo tempo. (...) Terminando a história, nos perguntamos quem seria a pessoa mais velha do assentamento para nos ajudar a plantar os caroços de manga. Ouvimos: minha vó, minha mãe! E então perguntamos se tinha alguém que sabia muitas histórias, e logo ouvimos "Seu Chamaru!". "E se perguntarmos pra ele como podemos plantar as mangas?". "E se formos agora?". "Então vamos?", "Vamos!!!". Todos correram para kombi, em mais uma aventura! Mas antes, criamos asas pra kombi com os tecidos que a Luiza levou, enfeitamos a kombi por dentro e saímos (...) voando para a casa do Seu Chamaru, todos se lambuzavam de manga, e íamos inventando as histórias sobre ele: "eu ouvi dizer que Seu Chamaru já chupou 100 mangas" e outras tantas, Pedro entrou na brincadeira e inventou histórias sobre Seu Chamaru e as mangas também.

Enquanto lanchávamos, Seu Chamaru nos contou histórias sobre a manga, falou da relação que a fruta tinha com os escravos, contou histórias que ele conhecia, e ainda confirmou ter comido 100 mangas! Arrumamos as coisas e perguntamos como poderíamos plantar as sementes, ele logo deu uns saquinhos pretos e nos ensinou até onde encher de terra. As crianças, super independentes, enchiam os saquinhos, até os pequenos fizeram, cada um enchendo o saquinho do seu jeito. (...) Depois, colocamos a semente, ainda um pouco mais de terra (...) e com uma carriola, levamos as mudas para 0 viveiro, onde regamos bastante. (Relato de atividade da Ciranda Infantil, $19 / 05 / 2012)$

\section{As crianças saíram da atividade com vontade de aprender outras coisas com o}

Seu Chamaru. Logo foi programada outra atividade por lá: uma oficina de enxerto.

Eu comecei contando a história e o Uruguaio encenando. Era um livrinho sobre mitos africanos, e escolhemos uma história que havia um monstro que "produzia" alguma coisa. A ideia era que com isso pudéssemos criar nosso próprio monstro que faz enxertos No meio da contação a Dora resolveu que ela que queria contar a história, e assim foi; pegou o livro, começou a ler, e mais crianças quiseram interpretar. No final da história, contamos que existia um monstro lá no assentamento, que fazia enxertos, e eles falaram que já sabiam e super entraram no clima; contando histórias sobre como ele era, ao mesmo tempo, em coletivo criaram esse monstro.

Então começamos a instigar, perguntando quais eram as cores do monstro: vermelho, azul e amarelo! (...) Depois o nome: vários nomes já conhecidos foram ditos, mas queríamos mais! Queríamos criar um nome próprio, com a nossa identidade. Então, com a junção de várias sílabas que iam sendo ditas fora criado o nome: Chamaru!! "E esse monstro tem uma música? Quando queremos chamar alguém para fazer enxerto o que devemos cantar?" - Foi assim que criamos o grito do Chamaru:

"Chamaru

É bicho, bicho do mato

Que não come gente

Educação | Santa Maria | v. 44 |2019

Disponível em: https://periodicos.ufsm.br/reveducacao 


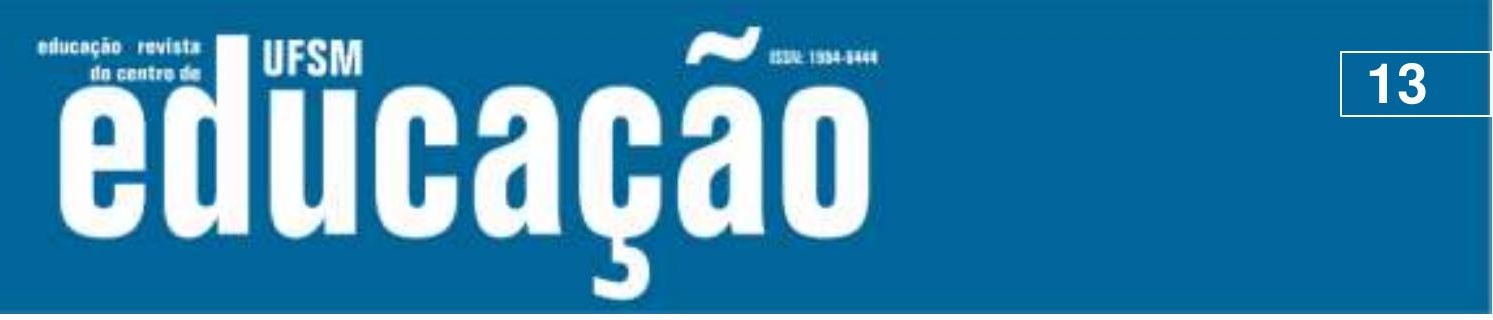

ISSN: 1984-6444 | http://dx.doi.org/10.5902/1984644435899

E faz muito enxerto."

Nos "fantasiamos de Chamaru", pintando o rosto com suas cores, e fomos para o lote do Seu Chamaru, onde fica o viveiro, cantando o grito do Chamaru, para chamá-lo, e também alguns gritos de ordem dos Sem Terrinha. Chegando lá fizemos uma roda, cantamos com o Seu Chamaru (...) sentamos para ouvir o Seu Chamaru nos explicar como se faz enxerto. Ele começou explicando com uma muda pequena, ali mesmo, em frente ao seu barraco, e depois nos levou para fazer em algumas árvores que ele tinha plantado em seu pomar. Então as crianças quiseram ir para o viveiro ver como estavam as mudas de manga que havíamos plantado. Eles ficaram maravilhados com a quantidade de mudas que o Seu Chamaru tinha feito nesse meio tempo. (Relato de atividade da Ciranda Infantil, 30/06/2012)

A relação entre a vida das crianças se conecta com as atividades educativas da Ciranda Infantil, agora por intermédio de um acampado, um senhor que via nas crianças a possibilidade de continuar a vida daquele futuro assentamento. Mobilizaram, assim, memória, histórias, as relações intergeracionais, uma cultura compartilhada, elementos que vão compondo a experiência de infância das crianças no acampamento e construindo suas identidades, enquanto sujeitos também daquela história.

\section{Sem Terrinhas construindo seu próprio lugar}

(...) Falamos da festa [de comemoração da ocupação do acampamento] e se eles se lembravam como eram a quatro anos atrás. Contaram de como chegaram lá, falaram que o Paulo desmaiou, bebezinho, durante o despejo. Contaram que eram menores. Perguntamos como eles estariam dali a quatro anos. Disseram que tudo seria melhor, ia ter luz, água, rua asfaltada. (Relato de atividade da Ciranda Infantil, 30/04/2011)

A experiência da luta social marca profundamente os sujeitos, modificando seu jeito de ser, de se relacionar com as pessoas e de pensar o mundo. Possibilita às mulheres, crianças e homens a produção de utopias, de projetar futuros ao construir e recontar a história de uma nova maneira. Contudo, a luta não se luta sozinha, lutase em coletividade e ao organizarem-se os sujeitos se educam e se transformam na coletividade em movimento (CALDART, 2012).

Neste sentido, a luta social na vida destas crianças passa a fazer parte do seu cotidiano. É a materialidade e a historicidade da luta da qual as crianças participam que educa, é o próprio movimento da luta concreta, em suas contradições, enfrentamentos, idas e vindas, conquistas e derrotas. (ROSSETTO, 2009, p. 79) 


\section{Us: \\ 2.

ISSN: 1984-6444 | http://dx.doi.org/10.5902/1984644435899

Entender a infância enquanto categoria estrutural (QVORTRUP, 2011) e as crianças como participantes dos processos de luta, contribui na reflexão sobre a infância Sem Terrinha. Por um lado, condicionada, pela questão agrária brasileira e o modo pelo qual as populações do campo vivem; ao mesmo tempo, sua experiência de infância é configurada pela vivência nos processos de luta que participam fazendo parte de um movimento social.

As crianças expressam sua experiência de infância das camadas populares e as culturas infantis nas atividades, no dia a dia da Ciranda Infantil. Como práticas culturais cotidianas, as crianças transformam a sua realidade em brincadeiras.

(...) Chegou o Cabecinha com um helicóptero de brinquedo preso em uma vara de pescar. Pronto, conversamos sobre o helicóptero, se eles já tinham visto e todos começaram a falar sobre o despejo, sobre o medo, que eles se machucaram, as crianças no barracão e logo começaram a brincar com o helicóptero de brinquedo. Um segurava e o fazia voar, enquanto todos os outros tentavam escapar. Não podíamos encostar no brinquedo pois sairíamos da brincadeira.

Quando as outras crianças chegaram, a brincadeira continuou e cresceu. Quem era atingido caía no chão e teria que ser resgatados pelos outros. A pessoa era carregada e levada para o "hospital", onde fazíamos massagem cardíaca e cócegas. (Relato de atividade da Ciranda Infantil, 30/07/2011)

Esses relatos trazidos em brincadeira, como cultura infantil, mostram que as experiências pelas quais passaram as crianças ficaram marcadas e que as expressam na leitura do mundo que fazem a partir da sua perspectiva de serem crianças.

Veremos aqui duas experiências das crianças Sem Terrinhas do acampamento Elizabeth Teixeira, em que elas se colocaram como sujeitos, protagonistas e construtoras da própria comunidade e dos seus espaços dentro do acampamento. Os relatos evidenciam elementos de como as crianças ocupam seu lugar na história do acampamento e se reconhecem como sujeitos ativos e protagonistas daquela história, para além de testemunhas oculares.

Como vimos, no início do acampamento as famílias construíram o espaço da Ciranda Infantil na área coletiva do acampamento. Um lugar "redondo", como as crianças contam, de estrutura hexagonal, com sete pilares de madeira, sendo um no meio e seis em volta, coberto com sapé. 


\section{U usm Autthabat}

ISSN: 1984-6444 | http://dx.doi.org/10.5902/1984644435899

No despejo todas as casas e estruturas coletivas foram destruídas pela polícia, inclusive a Ciranda Infantil. Na reocupação, construíram na área coletiva um barracão grande para servir de espaço de reuniões, eventos, comemorações, assembleias, etc. Esse barracão e as sombras das árvores do seu entorno foram sempre o espaço de acontecimentos das atividades da Ciranda Infantil.

Houve algumas tentativas de organização coletiva para construir um espaço das crianças. As próprias crianças estiveram presentes nos mutirões como construtoras e tomando decisões de como seria o espaço. São essas experiências das crianças que queremos observar ao trazer os relatos das tentativas de construção do espaço da Ciranda Infantil, protagonizadas, também, pelas crianças.

\section{Mutirão de construção do espaço físico da Ciranda Infantil}

No começo de maio do ano de 2010, aconteceu uma reunião entre os integrantes do coletivo Universidade Popular, mães, pais e demais moradores da comunidade com o objetivo de se encaminhar a construção do espaço físico da Ciranda.

Dentro do planejamento das atividades da Ciranda Infantil estava prevista a participação das crianças em algumas atividades dos mutirões. A primeira delas, era a apresentação do espaço das crianças para as mães que se configurou com: a construção coletiva do mapa do acampamento pelas crianças, desenhando as suas casas, outros espaços da comunidade e os desejos de cada criança para a construção da Ciranda Infantil; a participação das crianças no mutirão para levantar as paredes de taipa da cozinha do espaço da Ciranda; e a comemoração do dia das mães com a apresentação do mapa, dos sonhos, café da tarde coletivo e plantação de mudas de flores para demarcar a participação das crianças naquela construção coletiva.

A realização dessa atividade se dividiu em dois dias, dois sábados, como podemos ver nos relatos abaixo.

(...) Logo, todas fizeram o desenho da sua casa (...). Depois algumas fizeram desenhos sobre o que queriam que tivesse no acampamento, apresentando com frequência desenhos de balanço, tobogã, desenhos de parquinho, árvores, campo para jogar bola, e dois desenharam terra, foi muito legal. (...) decidimos que a confecção do mapa podia ser deixada, talvez, para a próxima semana. (Relato de atividade da Ciranda Infantil, 22/05/2010) 


\section{Usm oitibapat}

ISSN: 1984-6444 | http://dx.doi.org/10.5902/1984644435899

(...) Grudamos uns crafts [papel pardo] e colocamos no chão, em cima de uma lona para colarmos os desenhos. (...) conseguimos que cada uma colasse seu desenho e o mapa fosse montado. O Vinícius desenhou o barracão. Sua maior preocupação era que o barracão ficasse como o barracão original. Por isso ele fez um estudo do barracão e ficou um tempão desenhando. Fazia tempo que ele não aparecia nas nossas atividades. A maioria deles queria muito desenhar, mas só os que não haviam feito desenhos na semana passada que desenharam seus barracos.

Depois do almoço preparamos a mesa com os comes e bebes para as mães e pais. (...) Eram muitas crianças! Elas estavam ajudando no mutirão [amassando terra com água dentro de um grande buraco] e se divertindo muito. Depois a Vivian apresentou o mapa e contou sobre a atividade e os mutirões. Aí as crianças foram levando seus desenhos pra colarem no mapa, depois de apresentar o que haviam desenhado. Depois plantamos as flores. (...) Depois disso comemos muito (...) e partimos novamente pro mutirão. (Relato de atividade da Ciranda Infantil, 29/05/2010)

Os mutirões continuaram acontecendo e a participação das crianças era frequente. As crianças que moravam perto da área coletiva sempre apareciam para ajudar e outras iam acompanhando as mães e pais. Dessa maneira as crianças foram se identificando com o local da construção da Ciranda, utilizando-o para brincar mesmo antes do começo das construções.

No processo da construção do espaço da Ciranda Infantil fora decidido um tipo de construção alternativa com materiais disponíveis no próprio acampamento. $\mathrm{Na}$ estrutura circular, a parede seria em sua maior parte feito de taipa e uma parte seria constituída de garrafas plástica cheias de terra e areia. Decidiu-se conjuntamente que essa parte da parede seria responsabilidade das crianças, o que gerou um mutirão infantil como parte das atividades da Ciranda.

(...) enquanto a Luiza recordava a composteira e colocava mais matéria orgânica, eu dei uma atenção para as duas ou três crianças dispersas, ou melhor, mais interessadas nos instrumentos. Logo depois houve algumas que pularam corda, distribuímos um pedaço de doce e descemos com elas para - mutirão cantando uma música com muitos movimentos, bastante engraçada e que envolveu os grandes e pequenos.

A atividade ali no mutirão foi encher garrafas plásticas com areia e terra do formigueiro para construção de paredes. Todas as crianças se envolveram na labuta de encher e depois levar até a área que está sendo construída. $\mathrm{O}$ Tiradentes foi escolhido por uma das crianças a explicar o que faríamos com aquelas garrafas e, após a explicação (...) e o porquê da garrafa plástica, deixou 3 possibilidades de paredes para as crianças escolherem qual elas prefeririam. Acabou que a democracia prevaleceu e vamos utilizar métodos diferentes em cada trecho da parede. Fechamos as atividades com o hino dos Sem Terrinhas (Relato de atividade da Ciranda Infantil, 12/06/2010) 


\section{Lusm

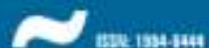

ISSN: 1984-6444 | http://dx.doi.org/10.5902/1984644435899

No decorrer dos meses, houve dificuldades de organização de novos mutirões e a construção desse espaço ficou parada. Aconteceram algumas tentativas de retomar as atividades de construção, mas sem sucesso. Pela ação do tempo, todo o trabalho coletivo foi se perdendo e o objetivo da construção do espaço físico das crianças não foi completado.

\section{Mutirão para a construção da Escolinha}

A Escolinha, como é chamada, é um espaço físico pensado inicialmente para abrigar as práticas educativas que acontecem no acampamento. Atualmente se desenvolve, principalmente, as aulas da EJA e, também, as atividades da Ciranda Infantil. É um local que abriga a biblioteca comunitária e é utilizado também para o atendimento da saúde do município, quando fazem as visitas na área, local de recebimento e distribuição das cestas básicas, realização de cultos religiosos, reuniões do assentamento, etc.

A construção surgiu da necessidade de ter um espaço físico que abrigasse as atividades educativas da EJA e da Ciranda Infantil. No processo de idas e vindas dessa demanda, um grupo de professoras da Faculdade de Engenharia Agrícola (FEAGRI) da Unicamp foram contempladas com recursos de um edital para a fabricação de tijolos ecológicos e o local escolhido para a execução do mesmo foi o acampamento Elizabeth Teixeira.

O projeto possibilitou à comunidade do acampamento o acesso a uma máquina de fabricação de tijolos de solo-cimento. Assim, alguns assentados e assentadas, junto com os e as estudantes, se organizaram em mutirões para a fabricação dos tijolos e, posteriormente, para a construção do espaço. As crianças participaram de todo o processo: produziram mais de 200 tijolos, participaram da construção e da finalização da obra.

Assim que chegamos no local do mutirão, Cirilo e Mário foram ver o que o Francisco estava fazendo (preparando a massa para o tijolo). Matheus ficou ali ajudando e Dora, eu e Mario começamos a desenhar a escolinha. Logo a massa ficou pronta e começamos a produção. Todos queriam ajudar e fomos conhecendo os processos da feitura do tijolo, Dora ia contando quantos fazíamos, Matheus tirava as fotos com a máquina da Carolina (filmava também, queriam fazer um filme de como se faz tijolo), os pequenos ajudaram também, eles colocavam a terra na fôrma, para que pudéssemos prensar. A 


\section{U

ISSN: 1984-6444 | http://dx.doi.org/10.5902/1984644435899

Rita ajudou bastante e parecia estar se divertindo muito levando os tijolos secos pra lá e pra cá.

Depois de um tempo, os pequenos encontraram um morro de areia e a brincadeira de escorregar começou! Todos brancos de areia! O lanche ficou em uma mesa dentro da igreja para que pudessem pegar a hora que quisessem. Lupita, sua mãe e os bebês também chegaram e foi muito bom! Ela ficou por perto, conversando, mas querendo participar. A Lupita logo se envolveu com o fazer dos tijolos. Igor foi essencial para o peso e contrapeso! Todos ajudaram da forma que puderam e foi uma manhã muito produtiva. No fim, 123 tijolos feitos pela criançada, pais e adultos. Terminamos com uma conversa sobre a escolinha. (Relato de atividade da Ciranda Infantil, $11 / 08 / 2012)$

(...) cantamos uma música (...) que a Lelê ensinou, que vai chamando o pessoal para entrar na fila, e fomos até a região que será a construção. (...) As meninas participaram mais da construção corporal das coisas para ter na ciranda: carteiras, balanço na árvore e escorregador. Então fomos até a construção de tijolos. Os meninos mais velhos foram na frente, e muitos quiseram vir de carro comigo (...). Os pequenos, Brian, Mario e Peter ficaram escorregando no bolo de areia. As meninas ficaram dentro da escolinha com a tarefa de contabilizar os tijolos. Chamamos todos para ajudar com os tijolos (...) deveríamos fazer uns 100. Fizemos 80. (Relato de atividade da Ciranda Infantil, 18/08/2012)

As crianças ajudaram a produzir uma boa quantidade dos tijolos utilizados na Escolinha. Depois contribuíram também no assentamento dos tijolos. Além disso, durante a construção, o acampamento recebeu uma doação de azulejos de diversos tipos para serem colocados como piso interno do espaço. Em conversas nos mutirões decidiu-se que as crianças poderiam escolher a maneira de montar algum desenho no piso com os azulejos.

Após a construção concluída, as crianças faziam uso do espaço ao seu modo, brincando com as coisas, mas que no olhar dos adultos eram lidos como bagunça, pois desorganizavam as cadeiras e mesas, liam os livros e não colocavam no lugar, "sujavam" o piso com os pés de terra, etc. Essas pequenas coisas foram virando reclamações dos adultos sobre as crianças.

Pensada para ser um espaço educativo para a comunidade do acampamento, foi se tornando espaço dos adultos, com as suas regras, lógicas e valores, e que parecia não comportar as lógicas das crianças daquele lugar, mostrando que esse ainda é um caminho a ser trilhado para mudança da lógica adultocêntrica (ROSEMBERG, 1976). 


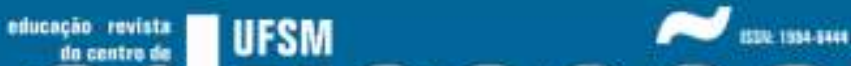

ISSN: 1984-6444 | http://dx.doi.org/10.5902/1984644435899

As atividades da Ciranda Infantil aconteceram ali desde a finalização da obra, como forma de tentar ocupar o lugar com as crianças. No entanto, é interessante ver como as crianças, mesmo com essa relação conturbada, se reconhecem nos tijolos, no piso, como partícipes e sujeitos da construção da Escolinha e do acampamento.

Cheguei a falar pro Pedro, quando ele estava na janela da Escolinha, "lembra de quando fizemos esses tijolos?". O Pedro abriu um sorrisão e disse pensativo: "é mesmo, né, Vandana...". Achei uma graça! (Relato de atividade da Ciranda Infantil, 09/03/2013)

\section{A história continua...}

Neste ano completam onze anos que as famílias do acampamento Elizabeth Teixeira ainda vivem em barracos de lona, de madeira, em habitações provisórias por conta do medo de investirem e terem de deixar a terra, ao mesmo tempo na esperança da legalização do assentamento.

Desde o final da pesquisa realizada, já houve novos pedidos de reintegração de posse em que as famílias tiveram que resistir para conseguirem se manter no território conquistado. De lá pra cá, mesmo com a insegurança da manutenção das famílias na área, o espaço coletivo continuou a ser construído.

Para as crianças, a grande conquista foi a construção do parque infantil, que teve início em 2015. Elas participaram desde a escolha da área, concepção do projeto, construção e cuidado posterior do parquinho. Ele foi terminado em 2017 e é o espaço atual de realização das atividades da Ciranda Infantil. Essa experiência de construção do parque infantil ainda não foi sistematizada e analisada, por esse motivo este artigo mostra as experiências anteriores de participação das crianças nas tentativas de construção do espaço das crianças no acampamento.

Contudo, o fato de hoje existir concretamente o espaço das crianças, nos faz refletir e compreender o lugar que as crianças foram ocupando na história do acampamento. Desde a ocupação da área as crianças além de sujeitos testemunhas tornam-se, ao olhar do pesquisador, também protagonistas da luta pela terra e construtoras ativas da história do acampamento, de suas histórias de vida e da experiência de infância compartilhada. 


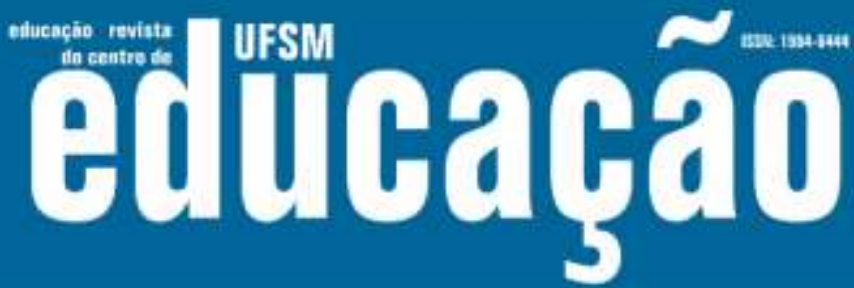

ISSN: 1984-6444 | http://dx.doi.org/10.5902/1984644435899

A ocupação, vista como um ato fundante de liberdade6, possibilita que a coletividade que ali instalada possa decidir sobre todas as dimensões da organização da vida daquele acampamento. Diante disso, o acampamento, retomando os dizeres de Eduardo Galeano na epígrafe deste artigo, torna-se também espaço das crianças constituírem a liberdade de serem crianças.

A partir das crianças, então, que se pôde compreender a realidade em que vivem, das lutas que travam, das resistências impostas, do descaso do Estado mas, ao mesmo tempo, da boniteza da esperança de construir o lugar vivido.

$\mathrm{Na}$ vivência com elas, o educador e pesquisador, exercitando seu olhar etnográfico, com o ímpeto coletivo de relatar a prática educativa com as crianças na Ciranda Infantil, foi modificando seu olhar, reconhecendo as crianças como sujeitos no mundo. Dessa maneira, os breves relatos aqui apresentados evidenciam a produção das culturas infantis, as produções de significados, leituras e interpretações do mundo feitas pelas crianças através das brincadeiras e atividades coletivas.

Assim, enxergar o espaço da Ciranda Infantil como espaço de produção de culturas infantis, contribui para compreensão das crianças no seus processos de identidade com a terra, identidade Sem Terrinha e como sujeitos protagonistas na luta pela terra. As atividades da horta, composteira, viveiro de mudas, enxerto, visibilizam a relação entre educação e vida, ao compreender que a vivência cotidiana de todos os espaços e sujeitos do acampamento constituem também a experiência de infância que compartilham.

Ao mesmo tempo, ao participarem da construção dos espaços coletivos do acampamento, e particularmente do espaço da Ciranda Infantil ou da Escolinha, elas vão se reconhecendo também como transformadoras e construtoras da realidade e se identificando com o lugar.

Analisar esses processos de construção de identidade das crianças com o lugar em que vivem, com a luta que participam, pode contribuir para que o mundo não apague mais essa história. É a possibilidade de deixar marcado na memória e experiência daquelas crianças essa trajetória que as vincula com uma luta maior, que

\footnotetext{
${ }^{6}$ Anotações da fala proferida por Luiz Carlos de Freitas na banca de qualificação da tese de doutorado de Edna Rodrigues Araújo Rossetto (2016), realizada em 10/11/2014.
} 


\section{U usm Alltapato

ISSN: 1984-6444 | http://dx.doi.org/10.5902/1984644435899

não se encerra nelas mesmas, pois é uma história que continua. No entanto, que elas possam ir se reconhecendo como sujeitos protagonistas que agem no mundo e que podem transformá-lo a partir da suas especificidades de ser criança, e de ser criança Sem Terrinha.

Parafraseando Karl Marx, "[as crianças] fazem a sua própria história, mas não a fazem segundo a sua livre vontade; (...) e sim sob aquelas com que se defrontam diretamente, legadas e transmitidas pelo passado" (MARX, 1977, p. 203).

\section{Referências}

CALDART, Roseli Salete. Pedagogia do Movimento Sem Terra. São Paulo: Expressão Popular, 2012.

CORSARO, William A. Sociologia da Infância. Porto Alegre: Artmed, 2011. FREITAS, Fábio Accardo de. Educação Infantil Popular: possibilidades a partir da Ciranda Infantil do MST. Dissertação (mestrado), Universidade Estadual de Campinas, Faculdade de Educação. Campinas, SP: [s.n.], 2015.

FERNANDES, Florestan. Folclore e Mudança Social na cidade de São Paulo. 3a ed. São Paulo: Martins Fontes, 2004.

GALEANO, Eduardo. De pernas pro ar - A escola do mundo ao avesso. Porto Alegre: L\&PM, 1999.

MARX, Karl. O dezoito Brumário de Luís Bonaparte. In: Textos, v. 3, São Paulo: Edições Sociais, 1977, p. 199-285.

MST. Educação Infantil: Movimento da vida, Dança do Aprender. Caderno de Educação n.12, São Paulo: MST, novembro 2004.

QVORTRUP, Jens. A infância enquanto categoria estrutural. Educação e Pesquisa, São Paulo, v. 36, n.2, maio/ago., 2010, p. 631-643.

ROSEMBERG, Fúlvia. Educação para quem?. Ciência e cultura, vol. 12, n. 38, 1976, p. 1467-1470.

ROSSETTO, Edna Rodrigues Araújo. Essa ciranda não é minha só, ela é de todos nós: a educação das crianças sem terrinha no MST. Dissertação (mestrado), Universidade Estadual de Campinas, Faculdade de Educação. Campinas, SP, 2009.

ROSSETTO, Edna Rodrigues Araújo. A organização do trabalho pedagógico nas Cirandas Infantis do MST: lutar e brincar faz parte da escola de vida dos Sem 


\section{工

ISSN: 1984-6444 | http://dx.doi.org/10.5902/1984644435899

Terrinha. Tese (doutorado), Universidade Estadual de Campinas, Faculdade de

Educação. Campinas, SP, 2016.

\section{Correspondência}

Fábio Accardo Freitas - Doutorando na Universidade Federal de Minas Gerais (UFMG), Belo Horizonte, Minas Gerais, Brasil.

Ana Lúcia Goulart de Faria - Professora doutora da Universidade Estadual de Campinas (UNICAMP), Campinas, São Paulo, Brasil.

Universidade Federal de Minas Gerais, Programa de Doutorado Latino-Americano em Educação. Av. Antônio Carlos, 6627, Pampulha. CEP: 31270-901, Belo Horizonte, Minas Gerais, Brasil.

E-mail: fabioaccardo@gmail.com - cripeq@unicamp.br

Recebido em 04 de dezembro de 2018

Aprovado em 27 de janeiro de 2019

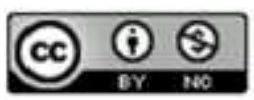

The is work is licensed under a Creative Commons Attribution-NonCommercial 4.0 International (CC BY-NC 4.0) 